$$
\frac{\beta}{\beta_{0}}=1-(0.658 \pm 0.006) x
$$

(4)と(5)より

$$
\frac{\beta}{\beta_{0}}=V_{0}-(0.04 \pm 0.01) x
$$

從つて

$$
v_{1} \frac{\beta_{1}}{\beta_{0}}-v+v^{\prime} \frac{\beta^{\prime}}{\beta_{0}}=-(0.04 \pm 0.01) x
$$

(7) 式中の $v_{1}$, 即ちゾル $1 \mathrm{cc}$ 中の澱粉粒子の容皘 は次の如くにして求められる。先ず (3)と(4)より

$$
v_{1}-v+v^{\prime}=0.6157 x
$$

搌粉の水和の如く，水素結合で結合している漛な結合 水の場合には水和に祭しての客榡變化は少ないと考えて よいから，上式で $v=v^{\prime}$ と扣けば

$$
v_{1}=0.62 x
$$

即澱枌 $1 \mathrm{~g}$ ○蓉䅡は $0.62 \mathrm{cc}$ となる。

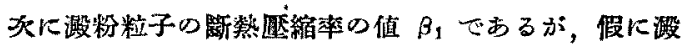
粉の分子が完全に水中でのび切っていて，分子内の個々 のセグメントの間の相左作用がないとすれば，麼縮亲は 零々なるが，實際には澱粉ゾルのコ口イド粒子は有限

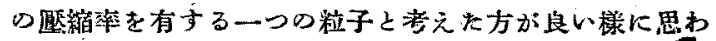

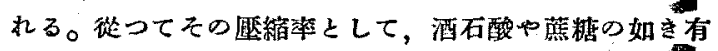

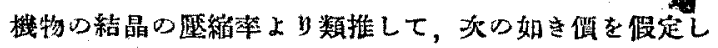
k。

$$
\beta_{1}=6 \sim 7 \times 10^{-12} \text { barye }^{-1}
$$

攵結合水の原縮倠としては，結合水が水素結合により

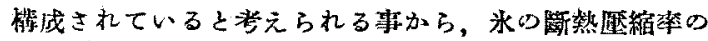

值了)上り類推して次の如く㯰いた。

$$
\beta^{\prime}=10 \sim 18 \times 10^{-12} \text { barye }^{-1}
$$

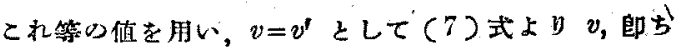
結合水の罳を求めると次の如き值となる。

$$
v=(0.15 \sim 0.23) x
$$

即ち㴛粉 $1 \mathrm{~g}$ について $0.15 \sim 0.23 \mathrm{cc}$ となる。 揤粉数の結合水についてはこれまで色々の方法で测定

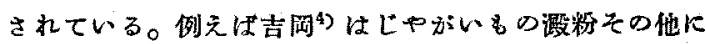

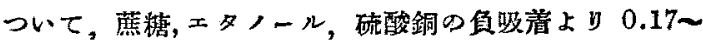

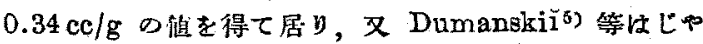

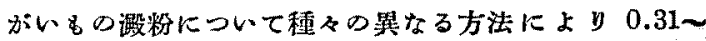
$0.37 \mathrm{cc} / \mathrm{g}$ の值を得ている。とれ等の值に等して現在求 めた值は若干の相逵があるが，使用した試料及び處理方 法の相違，己び澱粉粒子，結合水等の麻緮率の推定の不 正確さ等を洘虑すれば，との程度の不一致は致し方がな いであるら。

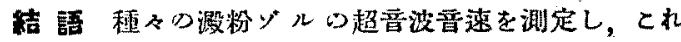

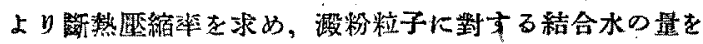
求めた。溊粉粒子及び結合水の厥縮率の值が正礶に定め られないので，はつきりした值は求められないが，これ 等に適常之思われる值を假定して求めた結合水の量の推 定值 $0.15 \sim 0.23 \mathrm{cc} / \mathrm{g}$ はこれで得られている值にか在 り近い值である。

(一部を炤和 24 年 11 月 13 日界面化學討論會にて 譜演)

\footnotetext{
3) L. Hal1, Phys. Rev. 73, 775 (1948).

4) 吉用尔年郎, 日化 71, 456 (1950).

5) A. V. DumansktY, R. V. Voilsekhovgkí, Chem. Abst. 43, $7781(1949)$.
}

(日本化成工業株式會社呼究所) (昭和 26 年 6 月 5 日受理)

ヘキシル試藥に依るカリウムの新定量法（第4 報）

定量法 $の$ 檢 討

佐藤省三・氏野善

序言

著者 (佐藤) は先に，へキシル(ジビクリルアミン) 試菜に㑢るカリウム心新定量法を報皆》した。然し沈溉 せるカリウム監の容耤の補正, 並びにーキンルナトリッ

1) 佐落. 日化 72, 450, 488, 490 (1951).
ム試藥を直接科量使用する方法に就いては報告しなかつ たが，鿒驗終了したので報告する。

\section{2. ヘキシルナトリゥムの秤量}

前包の辄告》に於いては文へシル試䒚の规定溶液を用 いたが，今间恃直接科滥使用する方法を檢討した。一キ 
シルナトリウム $\left(\mathrm{H}_{\mathrm{N}_{8}}\right)$ は $\left[\mathrm{O}_{6} \mathrm{H}_{2}\left(\mathrm{NO}_{2}\right)_{3}\right]_{2} \mathrm{~N} \cdot \mathrm{Na}$ むる租 成精合水はなく，且つ $250^{\circ} \mathrm{C}$ 位迄分解しない。從つ

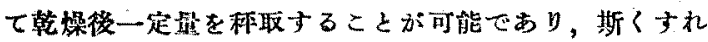
ば嫢定滀液を作る媔雜，並びにビぺットにて探取する際 の諽差が避けられる。

市販分析用へキシルナトリウム試葙 $2 \mathrm{~g}$ 探り, $110^{\circ} \mathrm{C}$ に乾嬠するに約 3 時間にて恒题となり，更に $130^{\circ} \mathrm{C} に$

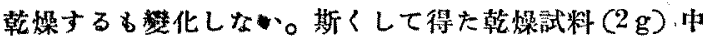
“の水分を Karl Fischer 法にて测定するに, $0.5 \mathrm{mg}$ 以 下だある。㷋つて本定祭法に於いては，便用する $\mathrm{H}_{\mathrm{Na}}$ は $\mathrm{I} \sim 3 \mathrm{~g}$ 故, $110^{\circ} \mathrm{C} 3$ 時間にて充分と类えられる。

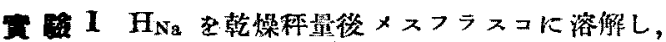
この溶液を50.03 cc のピペットにて探取し，過剩の硫酸

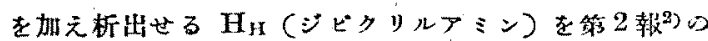
如くして科量した。用いたメスフラスコの器耧は，イ= $100.02 \mathrm{cc}, \square=100.03 \mathrm{cc}, 、=100.05 \mathrm{cc}$ でる。絬果 は次表に示す如くである。

\begin{tabular}{|c|c|c|c|c|c|c|}
\hline & \multicolumn{3}{|c|}{$110^{\circ} \mathrm{O}$ 乾燥㷋 $\mathrm{H}_{\mathrm{Na}} \mathrm{g}$} & \multirow{2}{*}{$\frac{\text { 科量值 }}{\mathrm{H}_{\mathrm{A}}{ }^{*} \mathrm{~g}}$} & \multicolumn{2}{|c|}{ 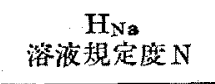 } \\
\hline & 2 洔間 & 4 洔間 & 6 時間 & & $A^{*}$ & B \\
\hline & 1.0096 & 1.0088 & 1.0088 & 0.4797 & 0.02186 & \\
\hline$\square$ & 2.0020 & 2.0013 & 2.0012 & 0.9516 & 0.04337 & \\
\hline & 3.9977 & 3.9968 & 3.9970 & 1.8991 & 0.08662 & 0.086 \\
\hline
\end{tabular}

* A は $\mathrm{H}_{\mathrm{Na}}$ の重量, B・は $\mathrm{H}_{\mathrm{H}}$ の重量上り炋第し た。

$\mathrm{H}_{\mathrm{H}}$ より求めた值が低くなるのは， $\mathrm{H}_{\mathrm{H}}$ の溶解亚びに

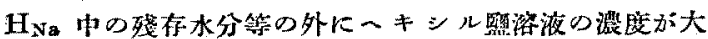

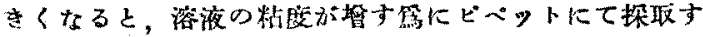
る際の䛇美に起因する。特に八の場合の雨者の美は後者

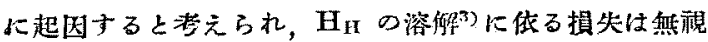
し得る。本定星法に於いては $\mathrm{H}_{\mathrm{N}_{\mathrm{L}}} 2 \mathrm{~g}$ 使用 し K $120 \mathrm{mg}$

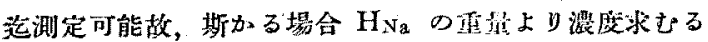

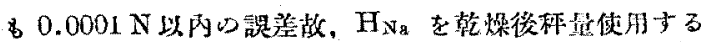
事が可能である。

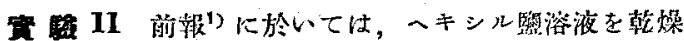
濾紅を用いて，沈漹せる $\mathrm{H}_{\mathrm{K}}$ 上り分雊した。然し斯加る

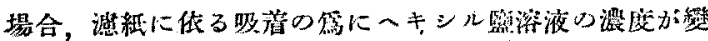
化する。グラスフィルターを使用すれば斯かる恐机はな

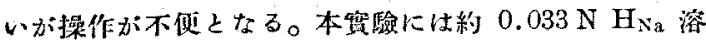
液を作り，イは直接ビぷットにて探取，口はグラスフィ

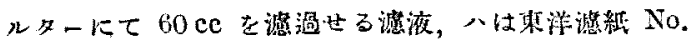

2) 佐蔡. 日化 72, 488 (1951).

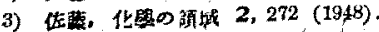

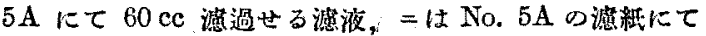

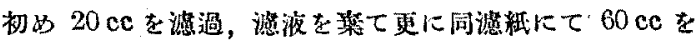

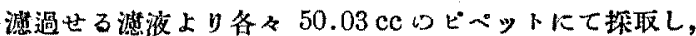

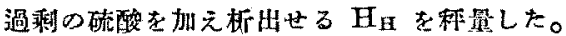

\begin{tabular}{|c|c|c|c|c|c|}
\hline & & 1 & 口 & $\therefore$ & $=$ \\
\hline $\mathrm{H}_{\mathrm{E}}$ & $\mathrm{g}$ & 0.7264 & 0.7266 & 0.7243 & 0.7257 \\
\hline$\eta$ & & 0.7257 & 0.7264 & 0.7239 & 0.7253 \\
\hline 7 & & 0.7262 & 0.7269 & 0.7236 & \\
\hline$"$ & 平均 & 0.7261 & 0.7266 & 0.7239 & 0.7255 \\
\hline 溶液: & 涨暖 & 0.03305 & 0.03307 & 0.03294 & 0.03302 \\
\hline
\end{tabular}

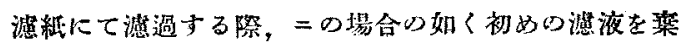

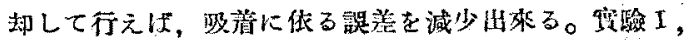

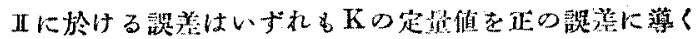
原因となる。

\section{3. 沈澄せる $\mathrm{H}_{K}$ の容積に就いて}

浓澱せる $\mathrm{H}_{\mathrm{K}}$ (へキシルのカリウム留) の答程を $v \mathrm{cc}$

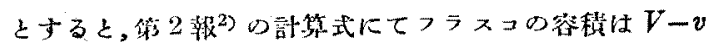
とすべきである。然し HKの量の少ない場合は $v$ を些 視し得るも，令间この點に就いて檢討を行つた。 $\mathrm{H}_{\kappa}$ の

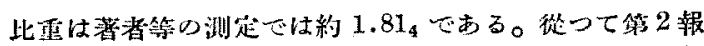
の諳算式は炏の如くなる。

A法 $\left[A n_{1}^{\prime}-\left(B n_{2}-C n_{3}\right) \times \frac{V-v}{D}\right] \times 39.10=\mathrm{K} \mathrm{mg}$

$$
v=\left[A n_{1}^{\prime}-\frac{V}{D}\left(B n_{2}-C n_{3}\right)\right] \times \frac{0.477}{1.81}
$$

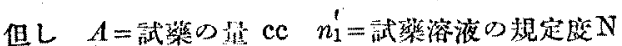

$B=\mathrm{H}_{2} \mathrm{SO}_{4} \quad$ " $n_{2}=\mathrm{H}_{2} \mathrm{SO}_{4}$

$C=\mathrm{NaOH}$ " $n_{3}=\mathrm{NaOH}$ "

$D=$ 用いた滤液の量 $c 0.477=\mathrm{H}_{\mathrm{K}}$ の分子㻎

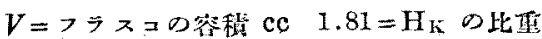

B法 $\left[A n_{1} \times 0.4392-\frac{W \times(V-v)}{D}\right] \times 89.01=\mathrm{K} \mathrm{mg}$

$$
v=\left(A n_{1} \times 0.4392-\frac{V \times W}{D}\right) \times \begin{gathered}
1.086 \\
1.81
\end{gathered}
$$

但L $\quad 1.086=\mathrm{H}_{\mathrm{K}} / \mathrm{H}_{\mathrm{IT}} \quad 89.01=\mathrm{K} / \mathrm{H}_{1 \mathrm{I}} \times 1000$ $439.2=\mathrm{H}_{\mathrm{II}}$ क分子其

前節の如くして $\mathrm{H}_{\mathrm{Na}}$ を秤取せる埸合， $\mathrm{H}_{\mathrm{Na}}$ の重量圭 $W_{1} \mathrm{~g}$ とし， $\mathrm{H}_{11}$ ，の科量值索 $W \mathrm{~g}$ とすると次式に依り カリウムめ昰圭水む。

$$
\begin{gathered}
{\left[W_{1} \times 0.9523-\frac{W \times(V-v)}{D}\right] \times 89.01=\mathrm{K} \mathrm{mg}} \\
v=\left(W_{1} \times 0.9523-\frac{V \times W}{D}\right) \times \frac{1.086}{1.81}
\end{gathered}
$$


但L $0.9523=\mathrm{H}_{\mathrm{Ir}} / \mathrm{H}_{\mathrm{Na}}$

\section{4. 實}

\section{驗}

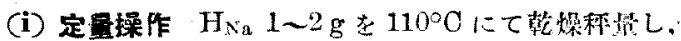

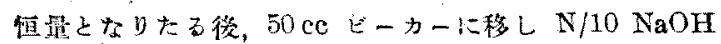

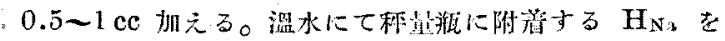

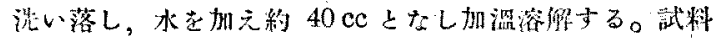

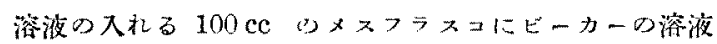
を注ぐ，ビーカーに附朔する $\mathrm{H}_{\mathrm{Na}}$ 溫液を水にて完全に

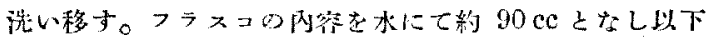

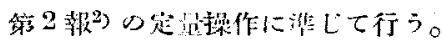

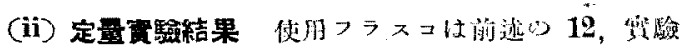
エにて伐用せるもの，ピペットは50.03 cc せるる。

\begin{tabular}{|c|c|c|c|c|c|}
\hline & 永收試料 & $H_{x_{a}}$ & $\mathrm{H}_{11}$ & 溫戊 & 補项值 \\
\hline & $\dot{\mathrm{K}} \mathrm{mg}$ & $W_{1} g$ & $W_{\mathrm{g}}$ & ${ }^{\circ} \mathrm{C}$ & ${ }^{*} \mathrm{~K} \mathrm{mg}$ \\
\hline 1 & $39 . I_{1}$ & $1.8+17$ & 0.6601 & 15 & 0.47 \\
\hline 八 & $" 1$ & 0.9279 & 0.2900 & $"$ & 0.71 \\
\hline 口 & $118.1_{3}$ & 1.6161 & 0.1119 & $"$ & 0.88 \\
\hline 1 & "I & 1.7571 & 0.1770 & "I & 0.71 \\
\hline 口 & $"$ & $2.7 \pi 11$ & $0.657 \pi$ & " & 0.47 \\
\hline 1 & $" 1$ & 1.8439 & 0.2196 & 20 & 1.13 \\
\hline ㅁ & $"$ & $1.8+50$ & 0.2269 & 25 & 1.71 \\
\hline
\end{tabular}

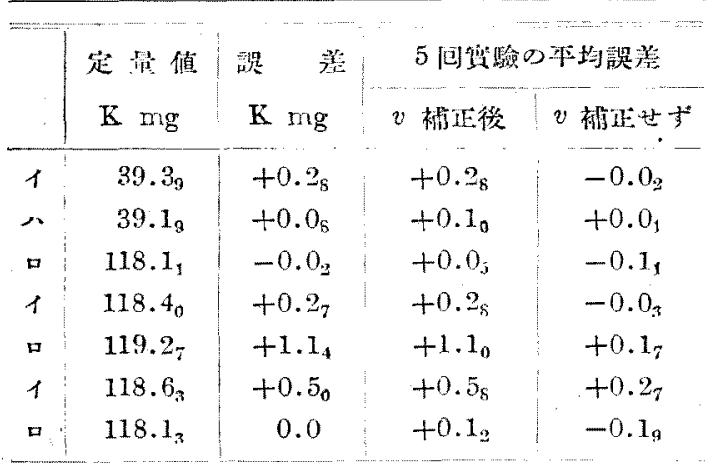

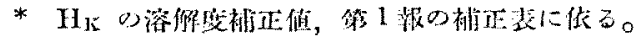

上笠り結果は，沈澱せる $\mathrm{H}_{\mathbf{K}}$ の容䅡 $v$ を㭪正せる場

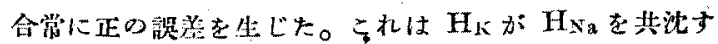

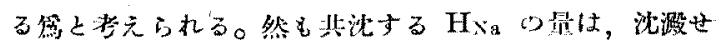

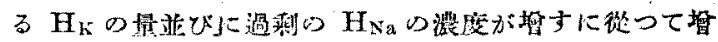

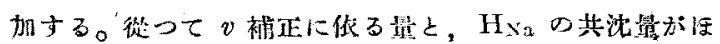

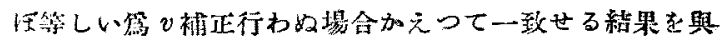

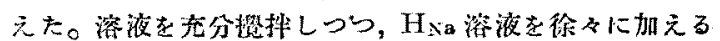

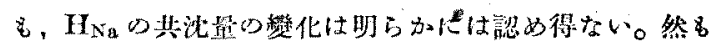

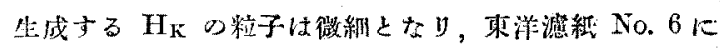
ても完正に泖別し得なくなる。

\section{5. 霬驗結果の總括}

(i) $\mathrm{H}_{\mathrm{Na}}$ を $110^{\circ} \mathrm{C}$ 厄乾燥し相长を得ることが可能

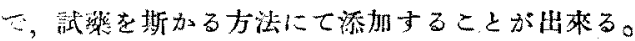

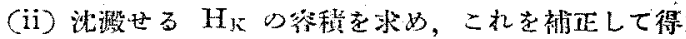

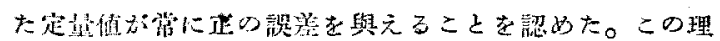

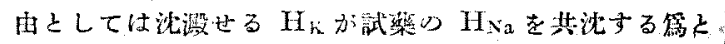

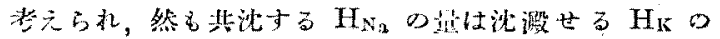

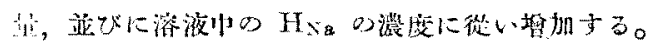

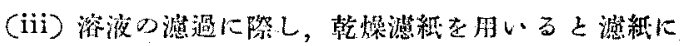

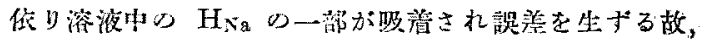
グラスフィルターの优用が望ましい。

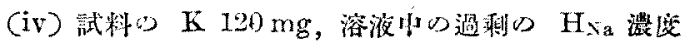
$0.01 \mathrm{~N}$. をると(添加せる $\mathrm{H}_{\mathrm{a}}$ は $1.9 \mathrm{~g} / 100 \mathrm{cc}$ ), 沈

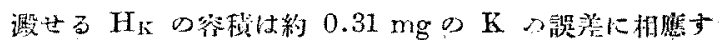

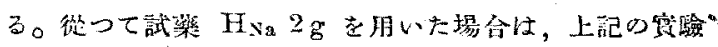

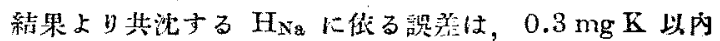

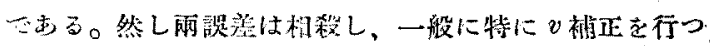

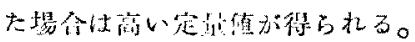

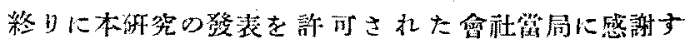
\%。 